\title{
AVALIAÇÃO DO USO DE RESÍDUO DE SERRAGEM DE PEDRA CARIRI COMO AGREGADO MIÚDO SOBRE O COMPORTAMENTO DE CAA
}

\author{
Brendhy Torres de Queiroz ${ }^{1}$; Mônica Batista Leite²; Uiliana Márcia da Silva Mercês \\ Farias $^{3}$ \\ 1. Bolsista PIBIC/CNPq, Graduando em Engenharia Civil, Universidade Estadual de Feira de Santana, e-mail: \\ brendhytorres@hotmail.com \\ 2. Orientador, Departamento de Tecnologia, Universidade Estadual de Feira de Santana, e-mail: \\ mleite.uefs@gmail.com \\ 3. Participante do projeto, Departamento de Tecnologia, Universidade Estadual de Feira de Santana, e-mail: \\ uilianamerces@yahoo.com.br
}

PALAVRAS-CHAVE: Resíduo de serragem de Pedra Cariri; Agregado miúdo; Concreto autoadensável.

\section{INTRODUÇÃO}

O setor da construção civil é o maior consumidor de minério de areia no Brasil, correspondendo a $62 \%$ do total consumido (VIEIRA; REZENDE, 2015). Os impactos socioambientais decorrentes da exploração desse minério, associados ao esgotamento de jazidas, tem fomentado estudos que visam incorporar resíduos, tanto da própria construção civil como de outros segmentos produtivos, na produção de argamassas e concretos.

No Brasil, em 2016, as exportações de rochas ornamentais e de revestimento totalizaram aproximadamente 2,5 milhões de toneladas (ABIROCHAS, 2017). A Pedra Cariri, rocha calcária laminada cuja exploração representa a principal atividade econômica dos municípios de Nova Olinda e Santana do Cariri - CE, por conta de métodos rudimentares empregados em seu processo produtivo se gera cerca de $70 \%$ de perdas nas etapas de lavra e beneficiamento (VIDAL; PADILHA, 2003). Estima-se que sejam gerados 850 t/ano de resíduo de serragem de Pedra Cariri (RSPC), proveniente da etapa de serragem da Pedra Cariri (BASTOS, 2014).

Estudos desenvolvidos anteriormente, com o intuito de avaliar o comportamento do RSPC em materiais a base de cimento, constataram que esse resíduo tem o potencial de uso como adição tipo fíler, além de elevar a coesão das misturas (SILVA, 2008; SUASSUNA et al., 2012; BASTOS, 2014; GUIMARÃES, 2014; GALVÃO et al., 2016; MERCÊS; MOURA, 2016; FARIAS, 2017).

Assim, esse estudo tem como objetivo avaliar a substituição parcial de agregados miúdos por RSPC em concretos autoadensáveis (CAA), verificando sua influência sobre os parâmetros de autoadensibilidade e resistência mecânica.

\section{MATERIAL E MÉTODOS}

Para produção do concreto autoadensável (CAA) foi utilizado o cimento Portland composto com pozolana (CPII-Z-32), com massa específica de 2,94 kg/dm ${ }^{3}$. O RSPC, utilizado em substituição parcial à mistura de agregados miúdos naturais, tem massa

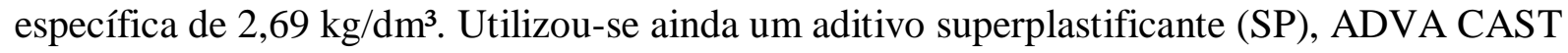
525 , a base de policarboxilatos, com massa específica de $1,06 \mathrm{~kg} / \mathrm{m}^{3}$, segundo informações do fabricante.

Como agregado miúdo, utilizou-se uma combinação binária de areias quartzosas: uma areia fina (AF), com Dmax de 1,2 mm e massa específica de $2,62 \mathrm{~kg} / \mathrm{dm}^{3}$, e uma areia média (AM), com dimensão máxima característica (Dmax) de 2,4 mm e massa específica de 2,61 
$\mathrm{kg} / \mathrm{dm}^{3}$. Foi utilizada uma composição de duas britas: uma brita com Dmax de $9,5 \mathrm{~mm}(\mathrm{~B} 9,5)$ e a outra, com Dmax de $19 \mathrm{~mm}$ (B19). A B9,5 apresentou massa específica de 2,69 kg/dm³ e a B19, $2,76 \mathrm{~kg} / \mathrm{dm}^{3}$. A composição granulométrica da mistura de agregados, miúdo e graúdo, foi traçada, para se adequar às faixas ideais estabelecidas por Melo (2005) para produção de CAA. Assim, trabalhou-se com uma composição final foi de $70 \%$ AF e $30 \%$ de AM para o agregado miúdo, e de $60 \%$ B9,5 e $40 \%$ de B19 para o agregado graúdo.

A dosagem do CAA foi realizada baseada no método Repette-Melo (MELO, 2005). Nesse estudo foram adotadas as relações a/c 0,57 e 0,70, o teor ideal de agregado miúdo de $45 \%$, em relação ao volume de argamassa, para a relação a/c 0,57 e $50 \%$ para a relação a/c 0,70, e o teor de substituição de $10 \%$ de RSPC em substituição à mistura de agregado miúdos naturais definidos e descritos na pesquisa de Farias (2017).

Conhecendo-se os teores de agregado miúdo e RSPC para cada relação a/c, procedeuse com os estudos na fase de concreto para determinação do teor ideal de agregado graúdo em relação ao volume de concreto e teor final de aditivo SP. Para a relação a/c 0,57 , o teor de agregado graúdo foi de $30 \%$ e o teor final de aditivo foi de $0,8 \%$. Já para a relação a/c 0,70 , estes teores foram de $28,5 \%$ e $0,7 \%$, respectivamente. Assim, os traços unitários finais, em massa, das misturas com RSPC foram '1,00:0,20:1,23:0,52:1,14:0,78' para o CAA de a/c 0,57, e '1,00:0,28:1,72:0,73:1,34:0,92 para o CAA de a/c 0,70, considerando a seguinte ordem de materiais secos (c:rspc:af:am:b9,5:b19).

Com o intuito de avaliar o efeito da substituição parcial da mistura de agregados miúdos naturais pelo RSPC, os concretos foram avaliados no estado fresco e no estado endurecido (Tabela 1). Misturas de CAA sem incorporação de resíduo, denominados C-REF, foram produzidas com o objetivo de comparar os resultados.

Tabela 1 - Ensaios realizados para avaliar CAA

\begin{tabular}{ccccc}
\hline Ensaios & $\begin{array}{c}\text { Idade } \\
(\text { dias })\end{array}$ & $\begin{array}{c}\text { N. de } \\
\text { CPs }\end{array}$ & $\begin{array}{c}\text { Faixa de } \\
\text { trabalho }\end{array}$ & Método de ensaio \\
\hline Espalhamento & - & - & 550 a 850mm & NBR 15823 - 2 (ABNT, 2010) \\
Funil V & - & - & $<9 \mathrm{~s}$ & NBR 15823 - 5 (ABNT, 2010) \\
Anel J & - & - & 0 a 25mm & NBR 15823 - 3 (ABNT, 2010) \\
Caixa L & - & - & $\geq 0,80$ & NBR 15823 - 4 (ABNT, 2010) \\
$\begin{array}{c}\text { axial } \\
\text { Resistência à compressão }\end{array}$ & $7-28$ & 08 & - & NBR 5739 (ABNT, 2007) \\
$\begin{array}{c}\text { Resistência à tração por } \\
\text { compressão diametral }\end{array}$ & $7-28$ & 08 & - & NBR 7222 (ABNT, 2011) \\
\hline
\end{tabular}

\section{RESULTADOS E DISCUSSÃO}

Os CAA produzidos foram avaliados quanto à capacidade de preenchimento, à habilidade passante e à resistência à segregação, conforme resultados da Tabela 2.

Tabela 2 - Propriedades do CAA no estado fresco.

\begin{tabular}{cccccc}
\hline \multirow{2}{*}{$\mathbf{a} / \mathbf{c}$} & Mistura & $\mathbf{D}(\mathbf{m m})$ & $\mathbf{F}-\mathbf{V}$ & $\mathbf{A}-\mathbf{J}$ & $\mathbf{C}-\mathbf{L}$ \\
& & $\mathbf{t}(\mathbf{s})$ & 4,6 & 39 & $\mathbf{H P}$ \\
\hline \multirow{2}{*}{0,57} & C-REF & 821 & 14,0 & 12 & 0,9 \\
& C-RSPC & 660 & 5,8 & 60 & 0,8 \\
\hline \multirow{2}{*}{0,70} & C-REF & 675 & 10,0 & 15 & 0,7 \\
& C-RSPC & 551 & 0,8 & 0,8 \\
\hline
\end{tabular}

D- diâmetro médio obtido no ensaio de espalhamento; F-V- tempo de escoamento no funil V modificado; A-Jespalhamento no Anel J; dF - diâmetro final obtido no ensaio com o anel J; HP - habilidade passante determinada pelo método da caixa $\mathrm{L}$. 
Verificou-se que a redução na relação a/c ocasionou aumento no diâmetro de espalhamento. Para a mistura C-REF-57 esse aumento correspondeu a 21,6\%, enquanto para a mistura C-RSPC-57, foi de 19,8\%. Esse mesmo comportamento foi observado por Kraus (2006) e Farias (2017). Tal fato pode estar associado à composição das misturas visto que, as misturas de relação a/c 0,70 apresentam maior volume de agregados e menor volume de pasta, o que faz com que haja maior atrito interno entre as partículas e redução no diâmetro de espalhamento.

Quanto ao uso de RSPC, constata-se que a substituição parcial da mistura de agregado miúdo pelo resíduo foi acompanhada de redução no diâmetro de espalhamento, demonstrando aumento na coesão das misturas. Para a mistura C-RSPC-70, tal redução foi equivalente a $18,4 \%$ e para a mistura C-RSPC-57, 19,6\%. Comportamento semelhante foi constatado por Hama \& Hilial (2017) e pode estar relacionado à adição de finos à mistura. Os finos possuem elevada superfície específica, adsorvem parte da água de amassamento, reduzindo a quantidade de água livre no concreto e, consequentemente, reduzem o espalhamento do CAA.

Em relação ao ensaio de funil $\mathrm{V}$, verificou-se que as misturas com substituição parcial das areias por RSPC, para ambas as relações a/c estudadas, apresentaram tempo de escoamento superior ao limite estabelecido na faixa de estudo $(<9 \mathrm{~s})$, o que comprova o aumento de viscosidade, que se deve também a uma redução da relação água/finos (a/f).

As misturas C-REF-70 e C-REF-57 apresentaram resultados do ensaio de anel J acima do limite superior da faixa de aceitação do estudo. No ensaio da caixa L,verifica-se que somente a mistura C-REF-70 se encontrou fora da faixa de aceitação. Constata-se que os concretos com RSPC apresentaram habilidade passante em fluxo confinado satisfatória, mantendo as características necessárias de fluidez e resistência à segregação.

Na Tabela 3 são apresentados os resultados médios de resistência à compressão axial e resistência à tração por compressão diametral, aos 7 e 28 dias de idade, seguidos do desvio padrão e coeficiente de variação das misturas estudadas.

Tabela 3 - Resultados de resistência mecânica.

\begin{tabular}{ccccc}
\hline \multirow{2}{*}{ Mistura } & \multicolumn{2}{c}{$\mathbf{f c} \pm \mathbf{S d}(\mathbf{C V})$} & \multicolumn{2}{c}{$\mathbf{f t} \pm \mathbf{S d}(\mathbf{C V})$} \\
& $\mathbf{M P a} \pm \mathbf{M P a}(\boldsymbol{\%})$ & $\mathbf{2 8}$ dias & $\mathbf{7}$ dias & $\mathbf{2 8 ~ d i a s}$ \\
\cline { 2 - 5 } & $\mathbf{7 d i a s}$ & $\mathbf{M P a}(\boldsymbol{\%})$ \\
\hline C-REF-70 & $19 \pm 0,3(1,6)$ & $23,7 \pm 0,3(1,1)$ & $2,1 \pm 0,1(2,4)$ & $2,7 \pm 0,1(2,1)$ \\
C-RSPC-70 & $16,3 \pm 0,3(1,8)$ & $19,2 \pm 0,9(4,6)$ & $1,9 \pm 0,1(2,7)$ & $2,1 \pm 0,0(1,6)$ \\
\hline C-REF-57 & $23,6 \pm 0,0(0,2)$ & $28,1 \pm 2,1(7,1)$ & $2,9 \pm 0,1(1,6)$ & $2,9 \pm 0,2(7,5)$ \\
C-RSPC-57 & $21,9 \pm 0,4(1,7)$ & $24,8 \pm 0,2(0,9)$ & $2,1 \pm 0,1(6,1)$ & $2,7 \pm 0,1(3,3)$ \\
\hline
\end{tabular}

Pela análise dos resultados, foi possível observar que houve redução nas resistências à compressão e à tração dos concretos C-RSPC-70 e C-RSPC-57 quando comparados com os respectivos concretos de referência. Tal comportamento pode estar associado a floculação das partículas de resíduo, com o consequente aprisionamento de água, fazendo com que haja menor disponibilidade de água no sistema para hidratar as partículas de cimento.

A mistura C-RSPC-70 apresentou as maiores reduções na resistência à compressão, sendo de $14 \%$ e $19 \%$, aos 7 e 28 dias, respectivamente. Com relação à resistência à tração, observa-se que aos 28 dias, a maior redução (22\%) foi apresentada pela mistura C-RSPC-70.

\section{CONSIDERAÇÕES FINAIS}

Os resultados obtidos no estudo mostram que no estado fresco, constatou-se que o RSPC, por conta de sua elevada superfície específica, influencia no aumento de coesão e 
viscosidade das misturas. No estado endurecido, houve redução nas resistências à tração e resistência à compressão do CAA com RSPC em comparação ao concreto de referência.

Em função da melhoria das propriedades dos CAA no estado fresco, nas quais se observou um aumento da coesão e da viscosidade das misturas com o uso do RSPC, sugere-se a ampliação dos estudos com esse material, de modo a consolidar sua aplicação na produção desses concretos.

\section{REFERÊNCIAS}

ABIROCHAS, Associação Brasileira da Indústria de Rochas Ornamentais. 2017 [online]. Balanço das Exportações e Importações Brasileiras de Rochas Ornamentais em 2016. Homepage: http://www.abirochas.com.br/noticia.php?eve_id=4062.

BASTOS, A. J. O. 2014. Avaliação do uso de resíduo de serragem de Pedra Cariri (RSPC) para produção de concretos convencionais. Universidade Estadual de Feira de Santana, MSc diss.

FARIAS, U. M. S. M. 2017. Produção de concreto autoadensável com uso de fíler calcário de resíduo de serragem de pedra Cariri. Universidade Estadual de Feira de Santana, MSc diss.

GALVÃO, J. S. DA S.; PITA, A. C. B. DE O.; MERCÊS, U. M DA S.; MOURA, W. A.; LEITE, M. B. 2016. Estudo do uso de resíduo de serragem de pedra cariri na produção de misturas autoadensáveis. In: XVI Encontro Nacional de Tecnologia do Ambiente Construído, São Paulo, p. 4195 - 4208.

GUIMARÃES, C. C. 2014. Avaliação de blocos de argamassa produzidos com Resíduo de Serragem de Pedra Cariri. Universidade Estadual de Feira de Santana, MSc diss.

HAMA, S. M.; HILAL, N. N. 2017. Fresh properties of self-compacting concrete with plastic waste as partial replacement of sand. Int J Sust Build Dev. 148.

KRAUS, Z. F. 2006. Investigação de misturas de argamassas para dosagem do concreto autoadensável contendo ora filer calcário, ora aditivo promotor de viscosidade em substituição ao filer. Universidade Federal de Santa Catarina, MSc diss.

MELO, K. A. 2005. Contribuição à dosagem de concreto auto-adensável com adição de filer calcário. Universidade Federal de Santa Catarina, MSc diss.

MERCÊS, U. M DA S.; MOURA, W. A. 2016. Comportamento mecânico de argamassas produzidas com resíduo de serragem de pedra Cariri. In: XVI Encontro Nacional de Tecnologia do Ambiente Construído, São Paulo, p. 4233 - 4246.

SILVA, A. D. A. da. 2008. Aproveitamento de rejeito de calcário do Cariri Cearense na formulação de argamassa. Universidade Federal de Pernambuco, MSc diss.

SUASSUNA, P. M.; BRASILEIRO, M. I.; PRADO, A. C. de A. 2012. Reaproveitamento do rejeito da extração e beneficiamento da pedra Cariri em massas cerâmicas. In: Encontro Universitário da UFC no Cariri, Ceará.

VIDAL, F. W. H.; PADILHA, M. W. M. 2003. A indústria extrativa da pedra cariri no estado do Ceará: problemas x soluções. In: IV Simpósio de Rochas Ornamentais do Nordeste, Ceará, p. $199-210$.

VIEIRA, E. G.; REZENDE, E. N. 2015. Exploração mineral de areia e um meio ambiente ecologicamente equilibrado: É possível conciliar?. Sustentabilidade em Debate. 6 (2): 171192. 